\title{
CORRELAÇ̃̃ ENTRE A INCAPACIDADE FUNCIONAL, IDADE E ENZIMAS SÉRICAS NAS DOENÇAS NEUROMUSCULARES
}

\author{
LINEU CESAR WERNECK*
}

RESUMO - Foram estudados 806 casos de diversas doenças neuromusculares, a fim de verificar se existe correlaçăo entre o grau de incapacidade funcional aferida pela escala de Vignos e Archibald (V\&A) e enzimas séricas (creatinoquinase, desidrogenase lática, aldolase, transaminase glutâmica oxalacética e pirívica). Foram utilizados testes para a análise do coeficiente de correlação simples (Pearson) e múltiplo. Foi encontrada correlaçăo positiva (piora progressiva da incapacidade) da V\&A com a idade em algumas doenças, como a distrofia muscular de Duchenne, distrofia fascio-escapulo-umeral, distrofia miotônica, miopatias com defeitos enzimáticos da cadeia respiratória e esclerose lateral amiotrofica. Por outro lado, foi detectada correlação negativa (melhora progressiva dos sintomas) na miopatia do multicore, miopatia benigna da infáncia com predomínio de fibras do tipo 1, deficiência de carnitina e dermatomiosite. A V\&A mostrou maiores correlaçőes $(p<0,05)$ entre as diversas enzimas séricas quando estudadas isoladamente na distrofia muscular de Duchenne, distrofia óculocrânio-somática, polimiosites e periarterite nodosa. Quando as enzimas foram analisadas em conjunto, através de teste de correlaçăo múltipla, verificou-se pequena correlação entre elas e a V\&A. Esta reduzida interrelação sugere que a utilizaçăo de diversas enzimas na análise longitudinal das doenças neuromusculares é limitada, nåo tendo aplicaçăo pratica, embora sejam muito importantes no diagnóstico.

PALAVRAS-CHAVE: enzimas séricas, doenças neuromusculares, incapacidade funcional; diagnóstico.

Correlation of disability with age and serum enzymes in neuromuscular disorders

SUMMARY - We attempt to correlate the patient's disability and serum enzymes (creatinekinase, lactic dehydrogenase, aldolase, glutamic oxalacetic and glutamic piruvic transaminase) in several neuromuscular disorders using the Vignos and Archibald scale (V\&A). In 806 cases we studied, serum enzyme levels and the V\&A disability using a computer for Pearson's correlation and regressive analysis. A good correlation of the V\&A with age suggested a progressive evolution (increased disability) in Duchenne muscular dystrophy, fascioscapulohumeral dystrophy, myotonic dystrophy, myopathies due to respiratory chain enzyme deficiency and amyotrophic lateral sclerosis. A negative correlation (decrease disability with age) was found for multicore myopathy, benign myopathy of childhood with type 1 predominance, carnitine myopathy deficiency and dermatomyositis. It was found a correlation $(p<0.05)$ of the V\&A and the level of specific serum enzymes with Duchenne muscular dystrophy, oculocraniosomatic dystrophies, polymyositis and polyarteritis nodosa. Using regression analysis, we found a weak interrelation between serum enzymes studied simultaneously and the V\&A. These weak relations suggest some limitation in the long term use of the five serum enzymes in the evaluation of neuromuscular disorders when compared with V\&A; although they are very important in the diagnosis.

KEY WORDS: serum enzymes, myopathies, neuromuscular disorders, diagnosis, muscle disability.

Normalmente na clínica diária, funçāo e força muscular são avaliadas utilizando-se a escala do Medical Research Council. Esta escala avalia cada músculo isoladamente ${ }^{6}$. Para poder estudar o

Estudo realizado no Serviço de Doenças Neuromusculares da Especialidade de Neurologia, Departamento de Clínica Médica, Hospital de Clínicas da Universidade Federal do Paraná, Curitiba. *Professor Titular de Neurologia. Aceite: 20-julho-1994.

Dr. Lineu César Werneck - Rua Ewaldo Schiebler 780 - 82530-160 Curitiba PR - Brasil. 
estádio funcional dos pacientes com miopatia e classificá-los sob o ponto de vista funcional, necessitamos escala que seja facilmente executada e disponivel, como a escala de Vignos e Archibald (V\&A) ${ }^{14}$. A V\&A foi montada para avaliar e classificar a incapacidade progressiva dos pacientes com distrofia muscular de Duchenne, permitindo obter informaçōes sobre o grau de envolvimento da funçăo motora da cintura pélvica e dos membros inferiores inicialmente, e, posteriormente, dos membros superiores. Tem pouca ajuda nos casos com comprometimento bulbar, mas permite idéia sobre o estádio clínico e a evoluçăo dos pacientes ${ }^{15.17}$. Por outro lado, as enzimas séricas refletem a destruíção muscular, podendo ser utilizadas no diagnóstico e seguimento dos pacientes com doenças neuromusculares, já tendo sido realizados alguns estudos procurando sua correlação com a V\&A, enfocando principalmente a distrofia muscular de Duchenne ${ }^{4,7,13,16}$.

No presente estudo, investigamos a correlação de diversas doenças com o nível de incapacidade da V\&A entre a idade e as alteraçōes das enzimas séricas creatinoquinase (CK), desidrogenase lática (DHL), aldolase (ALD), transaminase glutåmica oxalacética (TGO) e transaminase glutâmica pirúvica (TGP).

\section{MATERIAL E MÉTODOS}

Entre 1500 biópsias musculares do Serviço de Doenças Neuromusculares do Hospital de Clinicas da Universidade Federal do Paraná, foram selecionados 806 pacientes, envolvendo diversos tipos de doenças, cujo diagnóstico foi firmado por dados clínicos, laboratoriais, eletromiográficos, bioquímicos e histológicos. Esses pacientes foram classificados quanto a incapacidade motora na V\&A, conforme a incapacidade funcional ${ }^{14}: 0$ - Pré clínico. Todas as atividades são normais; 1 - Caminha normalmente. Não corre normalmente; 2 - Defeito na postura ou marcha; 3 - Sobe escadas apenas com corrimăo; 4 Deambula sem ajuda. Nāo sobe escadas; 5 - Deambula sem ajuda. Não levanta de cadeiras; 6 - Caminha só com muletas ou outro tipo de ajuda; 7 - Não deambula. Senta-se ereto em cadeiras. Consegue movimentar cadeira de roda, come e bebe sem auxflio; 8 - Senta-se em cadeira em apoio. Não movimenta cadeira de roda e năo bebe em copo sem auxilio; 9 - Não senta ereto sem suporte e é incapaz de beber ou comer sem auxilio; 10 - Confinado ao leito, necessita auxilio para todas atividades (Tabela 1 ).

Foram registrados os valores plasmáticos (número de vezes aumentado em relaçæōo as valores normais) para a CK, DHL, ALD, TGO e TGP de todos os casos. Para facilitar alguns calculos, as enzimas foram agrupadas em quatro categorias:1. Normal, quando os valores estavam dentro dos limites normais; 2. Aumento leve, quando os níveis se situavam entre o normal e até duas vezes o valor normal; 3. Aumento moderado, quando o nível estava acima de duas vezes $e$ iam até 10 vezes o valor normal; 4 . Aumento importante quando estavam acima de 10 vezes o valor normal.

Para a análise estatrstica foi utilizado computador, sendo realizadas correlaçðes através do coeficiente de correlaçăo de Pearson e pelo ajuste de equaçōes lineares multiplas ${ }^{3}$.

\section{RESULTADOS}

1. Correlacões da escala de Vignos e Archibald com idade. Foram encontradas correlações com probabilidade $(p)<0,001$ em distrofia muscular de Duchenne, $p<0,01$ em dermatomiosite, $p<0,05$ em distrofia fáscio-escápulo-umeral, distrofia miotônica, miopatia do multicore, miopatia por deficiência de carnitina e miopatias por deficiências de enzimas da cadeia respiratória. Devido ao grande número de casos, a significância estatística fica alta, apesar do coeficiente de Pearson ser relativamente baixo em valores absolutos (Tabela 2, Figs 1,2 e 3). Nas outras doenças, a correlaçăo foi muito pequena ou não houve correlação estatisticamente significante. Nas tabelas estăo relacionadas unicamente as doenças que tiveram algum significado estatístico.

2. Correlações entre a escala de Vignos e Archibald e enzimas séricas. $\mathrm{Na}$ análise das enzimas divididas nas categorias de normal, aumento discreto, moderado ou importante, notamos que existiram correlaçð̄es em graus variáveis em diversas doenças, com probabilidade diferentes. 
Tabela 1. Frequência na escala de Vignos e Archibald.

\begin{tabular}{|c|c|c|c|c|c|c|c|c|c|c|c|c|}
\hline \multirow{2}{*}{$\begin{array}{l}\mathbf{n}^{\circ} \mathbf{d e} \\
\text { casos }\end{array}$} & \multirow{2}{*}{ Doenças } & \multicolumn{11}{|c|}{ Graus na escala } \\
\hline & & 0 & 1 & 2 & 3 & 4 & 5 & 6 & 7 & 8 & 9 & 10 \\
\hline
\end{tabular}

DISTROFIAS MUSCULARES

146 Distrofia muscular de Duchenne

35 Distrofia muscular de Becker

8 Distrofia muscular inf, $c /$ herança autos. recessiva

65 Distrofia muscular cinturas pélvica-escapular

26 Distrofia muscular fáscio-escápulo-umeral

5 Distrofia escápulo-peroneal

5 Miopatias distais (Wellander e outras)

22 Distrofia óculo-crânio-somática

3 Distrofia óculo-faringéia

$\begin{array}{cccccccccc} & 2 & 11 & 49 & 22 & 16 & 13 & 22 & 10 & 1 \\ 1 & 2 & 6 & 16 & 7 & & 1 & 2 & & \\ & & & 2 & 3 & 2 & & 1 & & \\ & 3 & 8 & 25 & 10 & 6 & 4 & 7 & 2 & \\ 4 & 7 & 10 & 4 & 1 & & & & & \\ & 2 & 2 & 1 & & & & & & \\ & & 3 & & & & 1 & 1 & & \\ 10 & 11 & & & 1 & & & & & \\ & 3 & & & & & & & & \end{array}$

\section{DOENCAS MIOTONICAS}

52 Distrofia miotônica

7 Miotonia congênita (Thomsem e Becker)

$\begin{array}{lllllll}9 & 19 & 12 & 6 & 4 & 1 & 1\end{array}$

$\begin{array}{lll}4 & 2 & 1\end{array}$

\section{MIOPATLAS CONGÊNITAS}

13 Distrofia muscular congênita

5 Desproporção congênita de fibras

3 Miopatia nemalínica

4 Miopatia do core central

4 Miopatia do multicore

7 Hipotonia benígna congênita

4 Hipotonias e miopatias congênitas a esclarecer

4 Miopatia benígna congênita $c /$ predom. fibr. tipo 1

3 Miastenia grave congenita

$\begin{array}{lllllllllll} & & 1 & 2 & 1 & 1 & & 4 & 2 & & 2 \\ 1 & 1 & 2 & & & & 1 & & & \\ & 1 & 1 & & 1 & & & & & \\ & & 3 & & & & 1 & & & \\ 1 & & & 2 & 1 & & & & & \\ 1 & 2 & & 3 & 1 & & & & \\ 1 & & & 1 & & & & 2 & & \\ & 2 & & 1 & & 1 & & & & \\ 2 & & 1 & & & & & & & \end{array}$

\section{MIOPATIAS METABOLICAS}

8 Deficiéncia de carnitina

5 Deficiencia de camitina-palmitil-transferase

6 Deficiência de enzimas da cadeia respiratória

2 Deficiência de adenilato deaminase

3 Deficiência de maltase ácida

3 Deficiência fosfofrutoquinase e miofosforilase

9 Paralisia periódica hipocalemica

$\begin{array}{llllll}2 & 1 & & 2 & 2 & 1 \\ 4 & & & 1 & & \\ 1 & 3 & 1 & & & 1 \\ 1 & 1 & & & & \\ 1 & & 1 & 1 & & \\ 3 & & & & & \\ 5 & 4 & & & & \end{array}$

MIOPATLAS IMUNOLÓGICAS-INFLAMATÓRIAS

30

33

4

25

32

DOENCCAS DO NEURÔNIO MOTOR INFERIOR

7 Atrofia muscular espinhal infantil - Tipo 1

31 Atrofia muscular espinhal infantil - Tipo 2

56 Atrofia muscular espinhal juvenil

32 Esclerose lateral amiotrófica

POLINEUROPATIAS PERIFERICAS

18 Atrofia peroneal progressiva

18 Leucodistrofia metacromática

41 Doença de Hansen

22 Intoxicaçäo crônica por inseticidas

$\begin{array}{cccccccccc}1 & 8 & 6 & 7 & 4 & 1 & 1 & 2 & & \\ 3 & 5 & 9 & 6 & 1 & 3 & 2 & 1 & 2 & \\ & & 2 & 2 & & & & & & \\ 9 & 9 & 4 & 1 & 1 & & & 1 & & \\ 11 & 16 & 1 & 4 & & & & & & \end{array}$

$\begin{array}{llllllllllll}1 & & & & 1 & & 1 & 4\end{array}$

$\begin{array}{llllllllll}1 & 1 & 4 & 3 & 2 & 1 & 4 & 10 & 3 & 2\end{array}$

$\begin{array}{llllllll}2 & 5 & 11 & 21 & 9 & 2 & 3 & 3\end{array}$

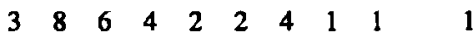


Tabela 2. Correlação entre idade e escala de Vignos e Archibald.

\begin{tabular}{|c|c|c|c|}
\hline $\begin{array}{l}n^{0} \text { de } \\
\text { casos }\end{array}$ & Doenga & $\mathbf{r}$ & $\mathbf{p}$ \\
\hline & DISTROFIA MUSCULARES & & \\
\hline 146 & Distrofia muscular de Duchenne & 0.74 & $* * *$ \\
\hline \multirow[t]{2}{*}{26} & Distrofia muscular fáscio-escápulo-umeral & 0.49 & $*$ \\
\hline & DOENÇAS MIOTÓNICAS & & \\
\hline \multirow[t]{2}{*}{52} & Distrofia miotônica & 0.34 & 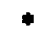 \\
\hline & MIOPATIAS CONGÊNITAS & & \\
\hline \multirow[t]{2}{*}{4} & Miopatia de multicore & -0.98 & * \\
\hline & MIOPATIAS METABOLLICAS & & \\
\hline 8 & Deficiência de carnitina & -0.75 & * \\
\hline \multirow[t]{2}{*}{5} & Deficiência de enzimas da cadeia respiratória & 0.89 & * \\
\hline & MIOPATIAS IMUNOLÓGICAS-INFLAMATÓRIAS & & \\
\hline 33 & Dermatomiosites & -0.46 & ** \\
\hline
\end{tabular}

Relacionadas somente as doenças que mostraram alguma significância.

$r=$ Correlação de Pearson; p: Probabilidade: *** = Probabilidade abaixo de 0.001; ** = Probabilidade entre 0.01 e $0.001 ; *=$ Probabilidade entre 0.05 e 0.01 .

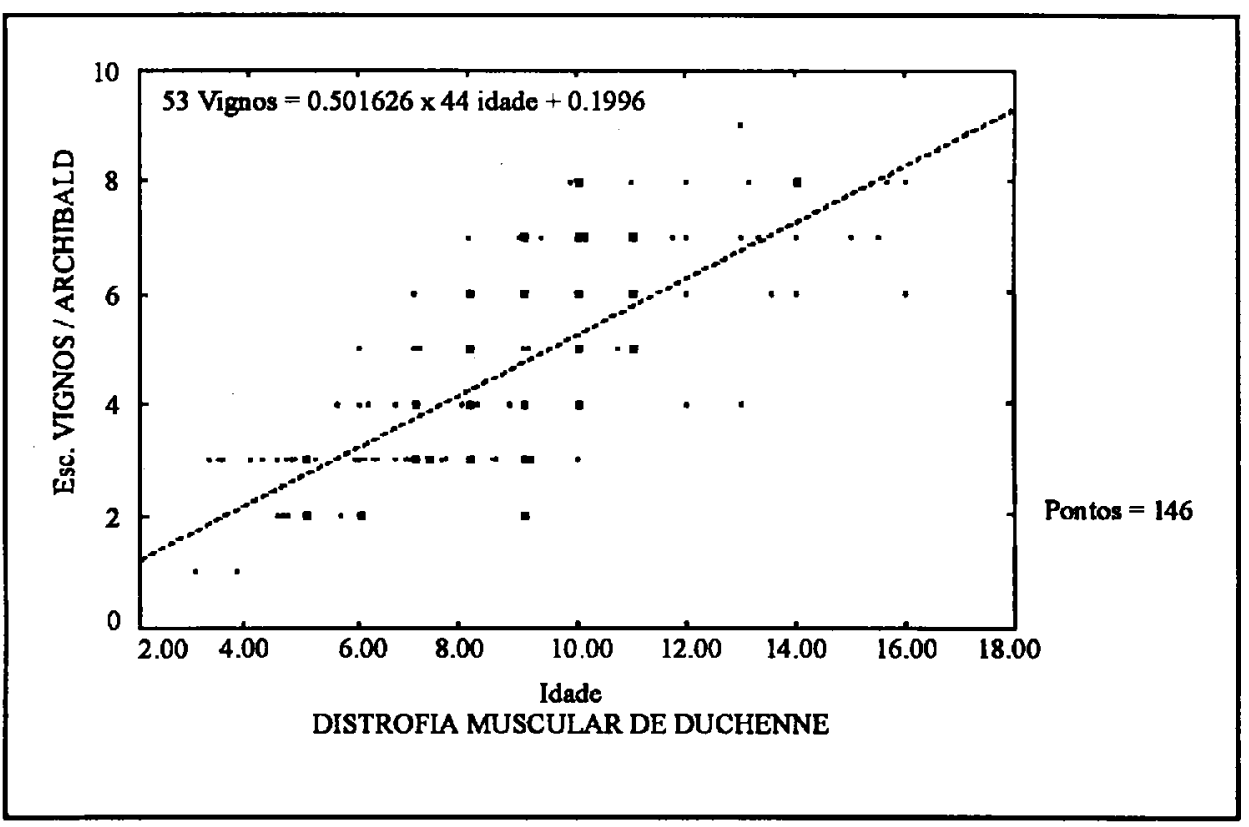

Fig 1. Correlaçäo da Escala de Vignos e Archibald com a idade na distrofia muscular de Duchenne. 


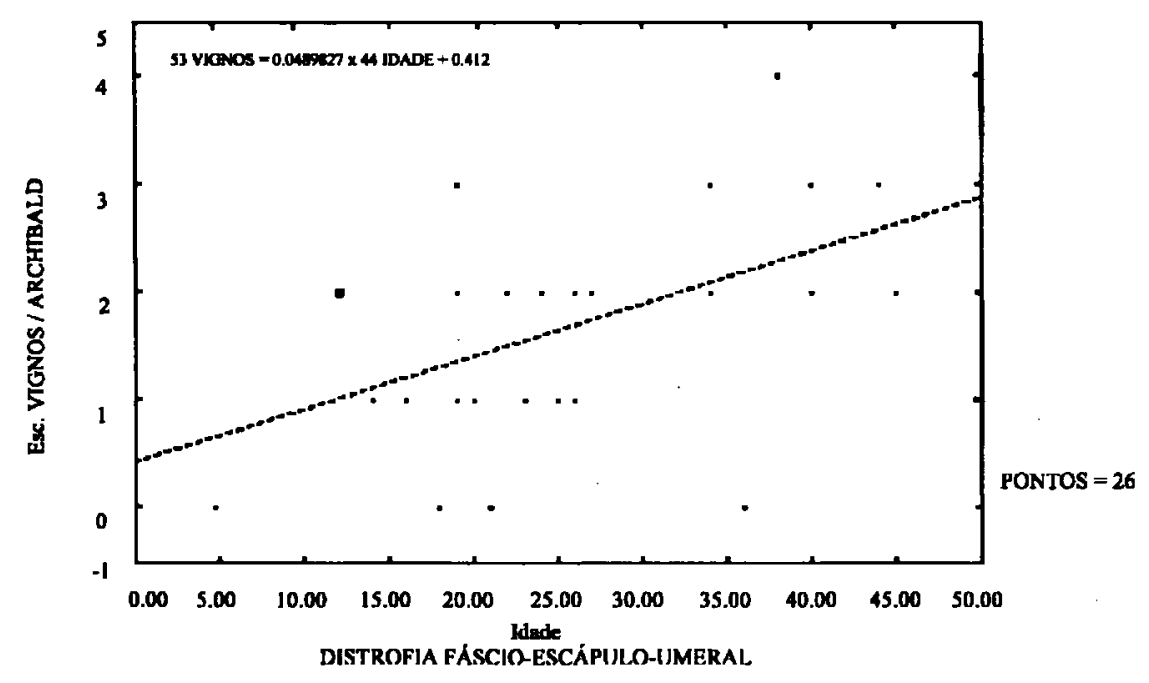

Fig 2. Correlação da escala de Vignos e Archibald com a idade na distrofia fáscio-escápulo-umeral.

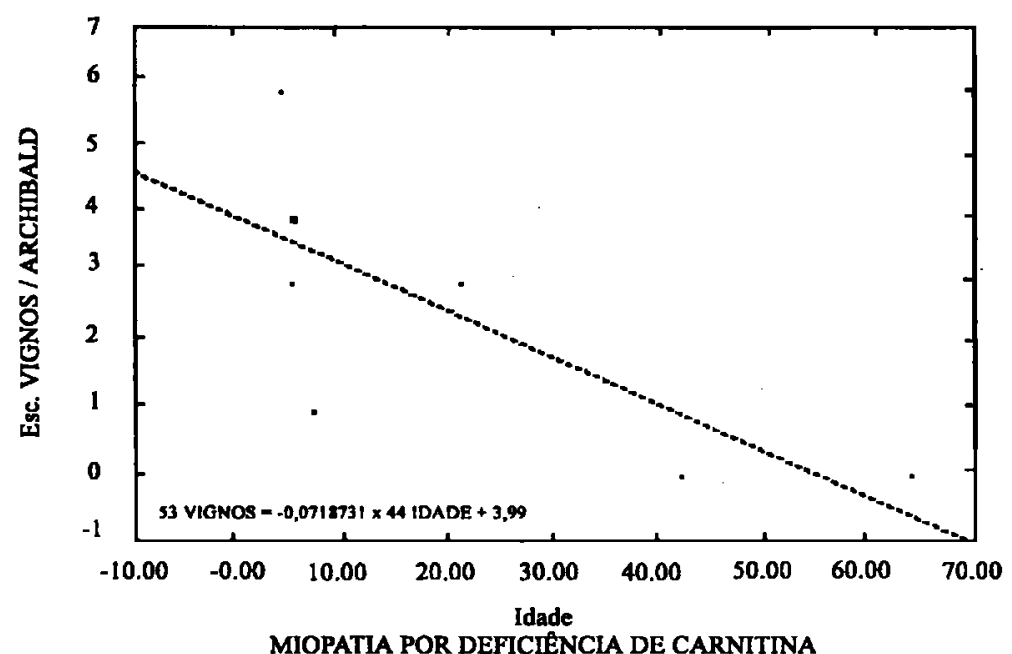

PONTOS $=8$

Fig 3. Correlaçäo da escala de Vignos e Archibald com a idade na miopatia por deficiência de carnitina antes do tratamento.

Tiveram probabilidade com $p<0,05 \mathrm{em}$ pelo menos uma enzima a distrofia muscular de Duchenne, distrofia muscular da infância com herança autossômica recessiva, distrofia óculo-crânio-somática, miopatias com deficiência de enzimas da cadeia respiratória, polimiosites, periarterite nodosa, atrofia muscular espinhal infantil tipo $2 \mathrm{e}$ atrofia peroneal progressiva (Tabela 3). 


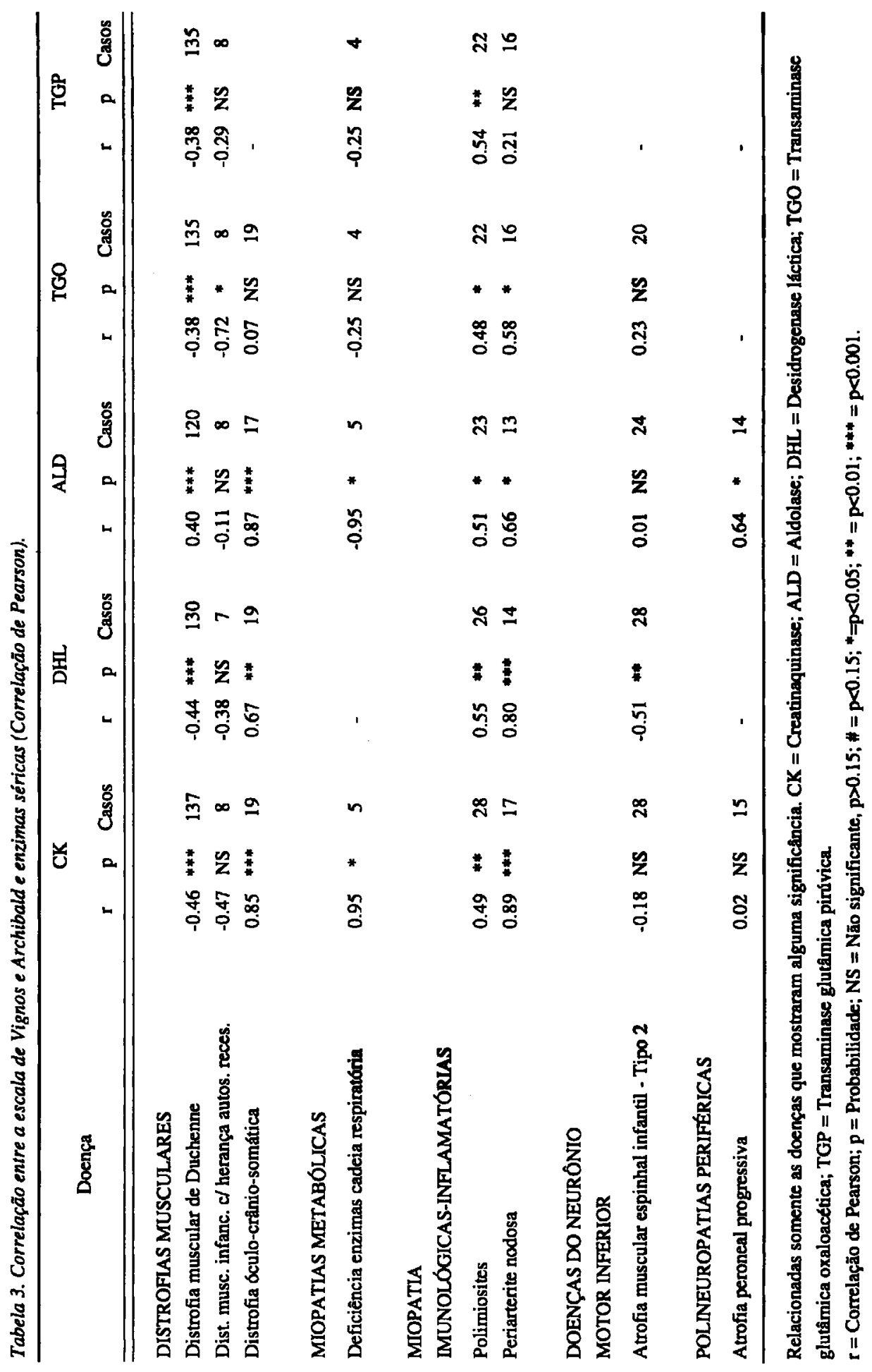


Tabela 4. Correlafão múltipla entre a escala de Vignos e Archibald e enzimas séricas.

\begin{tabular}{lcccccccc}
\hline \multicolumn{1}{c}{ Doença } & $\begin{array}{c}\text { Casos } \\
\text { Válidos }\end{array}$ & $\begin{array}{c}\text { Coef. Cor. } \\
\text { Múltipla }\end{array}$ & $\begin{array}{c}\text { Probab. } \\
\text { Assoc. }\end{array}$ & CK & DHL ALD TGO TGP \\
\hline \hline DISTROFIAS MUSCULARES & & & & & & & \\
Distrofia muscular de Duchenne & 100 & 0.65 & 0.0000 & $* * *$ & $*$ & & $*$ & \\
Distrofia muscular de Becker & 25 & 0.70 & 0.0019 & $* * *$ & & & & $*$ \\
Dist. musc. inf. c/ herança autos. reces. & 7 & 0.93 & 0.0147 & & & $*$ & $*$ & \\
Dist. musc. cinturas pélvica-escapular & 42 & 0.32 & 0.0340 & $*$ & & & \\
Dist. musc. fáscio-escápulo-umeral & 18 & 0.70 & 0.0069 & & $\#$ & & $* *$ \\
Distrofia óculo-crânio-somática & 17 & 0.86 & 0.0000 & $* * *$ & &
\end{tabular}

\section{MIOPATLAS METABOLICAS}

Def. de carnitina-palmitil-transferase

$1.00 \quad 0.0000 \quad * * *$

MOPATIAS

IMUNOLÓGICAS-INFLAMATÓRIAS

Polimiosites

Periarterite nodosa

$15 \quad 0.67$

0.0263

$11 \quad 0.98$

0.0000

Miastenia grave

28

0.65

0.0002

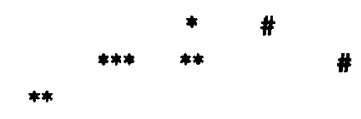

\section{DOENÇAS DO NEURONNIO} MOTOR INFERIOR

Atrofia muscular espinhal infantil-Tipo 2

22

0.49

0.0183

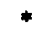

\section{POLINEUROPATIAS PERIFÉRICAS}

Atrofia peroneal progressiva

14

0.55

0.0411

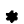

Relacionadas somente as doenças que mostraram alguma significância. CK: Creatinaquinase; DHL:

Desidrogenase láctica; ALD: Aldolase; TGO: Transaminase glutâmica oxaloacética; TGP: Transaminase glutåmica pirúvica.

\#: $p<0.15 ; *$ : $p<0.05 ; * *$ : $p<0.01 ; * * *$ p $<0.001$.

3. Correlação múltipla entre as enzimas e a escala de Vignos e Archibald. Tendo em vista as correlaçōes simples obtidas e a fim de verificar a correlação múltipla entre as variáveis, foi realizada a análise de regressão linear múltipla entre todas as enzimas e a V\&A. Foi possível o cálculo em somente algumas doenças, porque nem todos os casos possuíam todas as enzimas. Nāo houve uniformidade de correlações com a V\&A, sendo que em algumas doenças a única enzima com significado estatístico ( $p<0,05$ ) foi a CK (distrofia muscular de cinturas pélvica e escapular, distrofia óculo-crânio-somática, deficiência de carnitina-palmitil-transferase e miastenia grave), a DHL (atrofia muscular espinhal infantil tipo 2), a ALD (polimiosite e atrofia peroneal) e a TGO (distrofia muscular fascio-escápulo-umeral e distrofia muscular da infancia com herança autossomica recessiva). Houve combinaçāo de enzimas CK e TGP (distrofia muscular de Becker). DHL e ALD (periarterite nodosa) CK, DHL e TGO (distrofia muscular de Duchenne) (Tabela 4). 


\section{COMENTÁRIOS}

Obtivemos correlações da idade e V\&A em poucas doenças, sugerindo que, em algumas, os pacientes aumentavam o grau à medida em que a idade aumentava (correlação positiva) e, em outras, diminuía à medida em que os pacientes ficavam mais velhos (correlação negativa).

Existe dificuldade em obter uma escala que englobe todas as doenças e grupos musculares para termos de comparação. Mesmo a escala do Medical Research Council Memorandum para graduação da força muscular é falha pois o grau 4, quando comparado a medidas em dinamômetros, é responsável por $95 \%$ da força empregada ${ }^{8.9}$. Esta dificuldade fez com que grupos de investigação em distrofia muscular de Duchenne montassem um protocolo específico para esta doença. Subdividiram a escala do Medical Research Council conforme o grau de mobilidade das articulaçöes e, no teste funcional, além de utilizarem a V\&A, também utilizaram critérios para os braços e ombros $^{1,2.7}$. Para avaliaçōes a curto prazo, principalmente no estudo de medicaçōes, V\&A nāo é adequada, sendo preferível utilizar testes manuais da força muscular ou com dinamômetros.

Portanto, com base em dados e relatos da literatura, as aferições e graduações devem ser específicas para cada doença, devem incluir medidas em que a força ou a incapacidade estejam próximas ao normal e, em casos de protocolos terapêuticos, utilizar pacientes com o nível de força semelhante ${ }^{8,12,18}$.

Existem relatos de diversos autores de correlações entre o grau funcional dos pacientes baseado na V\&A com enzimas séricas, especialmente a CK e a piruvatoquinase e, menos, com outras enzimas ${ }^{49,13,16}$. Comparando nossos resultados com os da literatura, verificamos que se assemelham ao de Vassella e col., que acharam correlação entre o grau funcional baseado na V\&A e CK para evolução da distrofia muscular de Duchenne; as outras enzimas seriam menos sensíveis; não relatam relação em outras doenças ${ }^{13}$. Munsat e col. conseguiram obter correlações fracas entre o grau funcional dos pacientes, utilizando critérios da V\&A, na distrofia muscular de Duchenne, distrofia de cinturas pélvica e escapular e fáscio-escapulo-umeral. No entanto, em todos estes casos, o " $r$ " estava entre -0.39 e -0.34 , com nivel de p em torno de $0.05^{8}$. Fowler \& Pearson obtiveram correlação entre 0 grau funcional dos pacientes e de alguns critérios da V\&A com a CK, DHL, ALD, TGO e TGP na distrofia muscular de Duchenne, mas não na distrofia fáscio-escápulo-umeral, de cinturas pélvica e escapular e na miotônica ${ }^{4}$. No entanto, em outros estudos, como no de Niebrój-Dobosz e col., não foi encontrada correlação em nível significante entre os níveis de enzimas, idade dos pacientes e duração da doença; utilizaram uma escala própria de graduação, que não era a V\& $A^{10}$. Okinaka e col. utilizando uma escala própria, acharam relação da CK e ALD com a idade e agravamento da doença na distrofia muscular de Duchenne e não notaram elevação em doenças neurogênicas" Também Zitter e col. acreditavam que a CK e o declínio da força muscular da distrofia muscular de Duchenne, baseado na V\&A, relacionava-se mais com o grau de atividade física que com a progressão da doença ${ }^{17}$.

Como verificamos neste estudo, as enzimas séricas podem se reduzir conforme aumente a incapacidade na V\&A, como na distrofia muscular de Duchenne. Com a evoluçāo, na distrofia muscular de Duchenne a massa muscular vai se perdendo, com consequente redução da oferta de enzimas para a circulação; esta redução tem relação com a V\&A. Outras doenças podem também ter reduçāo das enzimas séricas e diminuição da incapacidade, conforme respondam ao tratamento ou fazendo parte da história natural da doença, como ocorre com a dermatomiosite e deficiência de carnitina, por preservar as fibras musculares da necrose e impedir a passagem das enzimas para a circulação. Este fenômeno não é uniforme para todas as doenças, pois vai depender muito do processo patogênico e da capacidade de depuração das enzimas de cada paciente.

Encontramos maiores correlaçōes das enzimas e a V\&A na distrofia muscular de Duchenne, distrofia óculo-crânio-somática, polimiosites e periarterite nodosa. $\mathrm{Na}$ interrelaçāo das diversas 
enzimas com a evoluçăo na V\&A, verificamos significância estatística no grupo das distrofias musculares e miopatias imunológicas-inflamatórias. A falta de interrelação nas outras doenças pode ser devida ao fato de que a V\&A foi feita para a distrofia muscular de Duchenne. Como a distrofia muscular de Duchenne, no início, compromete principalmente os membros inferiores e só tardiamente os membros superiores, a V\&A reflete esta evolução. Somente aparece na escala o acometimento dos membros superiores após o grau $8 \mathrm{e}$, portanto, casos de distrofia fáscio-escápulo-umeral ou 6́culo-crânio-somática entrariam no registro muito tarde, no estadio final. A presença de discriminação de algumas enzimas em algumas doenças e a falta noutras podem ser devidas ao metabolismo diferente de cada enzima e à gravidade do processo patogênico.

Se não é possível obter correlação adequada com todas as enzimas nas doenças neuromusculares, a elevação de determinadas enzimas auxilia no diagnóstico. Embora as enzimas não permitam fazer uma projeção adequada da evolução em todas as doenças que envolvem o sistema muscular, sāo uteis principalmente no grupo das distrofias musculares e miopatias imunologicasinflamatórias. Devemos sempre lembrar que as enzimas devem ser avaliadas em conjunto com os dados clínicos, pois cada doença tem época de ínicio, apresentação clínica, evoluçāo, duraçāo e tratamento diferentes.

\section{REFERENCIAS}

1. Brooke MH, Fenichel GM, Griggs RC, Mendell Jr, Moxley R, Miller JP, Province MA \& The CIDD Group. Clinical investigation in Duchenne dystrophy: 2. Determination of the power of the therapeutic trials based on the natural history. Muscle \& Nerve 1983, 6: 91-103.

2. Brooke MH, Griggs RC, Mendel Jr, Fenichel GM, Shumate JB, Pellegrino RJ. Clinical trial in Duchenne dystrophy. 1. The design of the protocol. Muscle \& Nerve 1981, 4: 186-197.

3. Colton T. Statistics in medicine. Boston: Little, Brown, 1974.

4. Fowler WM, Pearson CM. Diagnostic and prognostic significance of serum enzymes: 1. Muscular dystrophy. Arch Phys Med Rehabil 1964, 45: 117-124.

5. Griggs RC, Moxley RT, Mendel JR, Fenichel GM, Brooke MH, Pestronk A, Miller JP, Cwik VA, Pandya S, Robison J, King W, Signore L, Schierbecker J, Florence J, Matheson-Burden N, Wilson B. Duchenne dystrophy: randomized controlled trial of prednisone (18 months) anb azathioprine (12 months). Neurology 1993, 43: 520-527.

6. Medical Research Council. Aids to the examination of the peripheral nervous system. London: HMSO. 1976, Memorandum 45.

7. Mendel JR, Florence J. Manual muscle testing. Muscle \& Nerve 1990, 13 (Suppl): 16-20.

8. Munsat TL. Clinical trials in neuromuscular disease. Muscle \& Nerve 1990, 13 (Suppl) :3-6.

9. Munsat TL, Baloh R, Pearson CM, Fowler W Jr. Serum enzyme alterations in neuromuscular disorders. JAMA. 1973; 226: 1536-1543.

10. Niebroj-Dobosz I, Jedrzejowska H, Hetnarska L. Blood enzymes in Duchenne's progressive muscular dystrophy and their correlation with the clinical and histological pictures. Acta Med Pol (Warszawa) 1970, 11: 387-393.

11. Okinaka S, Kumagai H, Ebashi S, Sugita H, Momoi H, Toyokura Y, Fujie Y. Serum creatine phosphokinase. Arch Neurol 1961, 4: 520-525.

12. Ringel SP. Specific tests for polymyositis. Muscle \& Nerve 1990, 13 (Suppl): 40-42.

13. Vassela $F$, Richtterich $R$, Rossi $E$. The diagnostic value of serum creatinekinase in neuromuscular and muscular disease. Pediatrics 1965, 35: 322-330.

14. Vignos PJ, Archibald KC. Maintenance of ambulation in childhood muscular dystrophy. J Chronic Dis 1960, 12: 273-290.

15. Vignos PJ, Spencer GE, Archibald KC. Management of progressive muscular dystrophy of childhood. JAMA 1963, 184: 89-110.

16. Zatz M, Shapiro LJ, Campion DS, Oda E, Kaback MM. Serum pyruvate-kinase and creatine-phosphokinase in progressive muscular dystrophies. J Neurol Sci 1978, 36: 349-362.

17. Zitter FA, Alsop KG, Tyler FH. Assessment of muscle strenght in Duchenne muscular dystrophy. Neurology 1977, 27: 981-984. 